\title{
BERNARDO CARVALHO LÊ SADE: TRAIÇÃO E HORROR EM MEDO DE SADE
}

Rafael Zamperetti Copetti

Doutorando em Teoria da Literatura - UFSC

Resumo: Neste ensaio são discutidos pontos de contato entre a obra do Marquês de Sade e o romance Medo de Sade, de Bernardo Carvalho, a partir de considerações de autores como Pierre Klossowski e Georges Bataille.

Palavras-chave: Literatura brasileira; Romance; Bernardo Carvalho.

Abstract: This essay discusses some contact sites between Sade's work and Bernardo Carvalho's novel Medo de Sade from considerations by authors such as Pierre Klossowski and George Bataille.

Keywords: Brazilian's Literature; Novel; Bernardo Carvalho. 
Georges Bataille, em seu texto "Sade" (BATAILLE, s/d), sugere que o momento em que se deu a Revolução Francesa poderia ser considerado, em princípio, pobre, se observado do ponto de vista literário. Haveria, entretanto, segundo sua proposta, uma exceção: a obra do marquês de Sade, escritor que permaneceu grande parte de sua vida (1740 - 1814) encarcerado em virtude de sua obra literária e filosofia libertina. Ainda no século XX, constata, títulos como A filosofia na alcova e Justine ou história de Juliette causavam repulsa.

Bataille evidencia também que Sade e sua obra se encontram interligados com a Revolução Francesa, pois o sentido desta está, ainda que de forma singular, contido nos planos do marquês. Tais projetos se relacionariam com o desejo de destruição, tanto de objetos quanto de pessoas. O fim do pensamento clássico, isto é, da epistémê que possibilitou a gramática geral e a história natural, diz Foucault, "coincidirá com o recuo da representação, ou, antes, com a liberação, relativamente à representação, da linguagem, do ser vivo e da necessidade" (FOUCAULT, 2000, p. 289).

No princípio de Sade meu próximo, Pierre Klossowski (KLOSSOWSKI, 1985) argumenta que o ato de escrever "supõe uma generalidade à qual um caso singular reivindica adesão e, por isso, se compreende a si mesmo no domínio dessa generalidade" (KLOSSOWSKI, 1985, p. 16) e, ainda, que o marquês de Sade entenderia tal ato desta forma tendo em vista que o "instrumento da generalidade", em sua época, teria sido "a linguagem logicamente estruturada da tradição clássica”, cuja estrutura foi restabelecida através da comunicação a normatividade da "espécie humana nos indivíduos", a qual, por sua vez, garantiria "a conservação e a propagação da espécie".

Daí que, de acordo com Klossowski, a necessidade intrínseca do ser humano de se reproduzir e de perpetuar a espécie tenha encontrado seu agente persuasivo na linguagem, através do estabelecimento de uma "reciprocidade de persuasão que propicia a permuta das singularidades individuais no circuito da generalidade" (KLOSSOWSKI, 1985), reciprocidade que ocorreria apenas "segundo o princípio de identidade ou princípio de contradição, que faz cindir a linguagem logicamente estruturada com o princípio geral do entendimento, ou seja, a razão universal” (KLOSSOWSKI, 1985, p. 16-17).

A partir destas observações é possível perceber a origem da noção sadiana de monstruosidade integral, conceito que parece estar relacionado ao fato de o marquês de Sade buscar estabelecer uma contrageneralidade que permita a ocorrência de uma troca entre casos particulares de perversão, os quais teriam como característica a inexistência de estrutura lógica, caso a generalidade normativa seja tomada como base de comparação. E, já que Sade 
considerava a contrageneralidade um dos elementos que possibilitam a ocorrência da perversão, Klossowski sugere que o marquês entenda esta contrageneralidade como sendo um dos elementos que compõe a generalidade. Isto é: o ateísmo declarado pela razão normativa estaria destinado a mesclar a generalidade existente e a contrageneralidade (KLOSSOWSKI, 1985, p.17).

Esta opção pelo modo perverso, isto é, por uma forma que não possui um conjunto de regras e princípios estabelecidos, seria uma maneira de apontar a razão como atéia, já que esta, a razão, perceberia que a noção de Deus modifica de forma não lógica sua própria autonomia. E, se o cerceamento da autonomia da razão pela noção de Deus se dá de forma ilógica, é possível entender que o conceito de Deus é, portanto, também monstruoso e, por conseguinte, o ponto de partida dos diversos comportamentos perversos e monstruosos.

Entretanto, Klossowski chama a atenção para uma importante crítica formulada por Sade, ainda que de forma tácita: a crítica da razão normativa, que se daria, segundo o ensaísta, através do questionamento da maneira pela qual a razão normativa poderia vir a absorver aspectos que vão contra a manutenção da espécie humana, já que ela própria, a razão normativa, não "se renova em seu próprio conceito" (KLOSSOWSKI, 1985, p. 18). Ou seja, a intenção do marquês seria tornar o pensamento independente de "toda a razão normativa preestabelecida". Uma possível solução para esta questão passaria pelo ateísmo integral, o qual efetivamente poderia dar cabo da razão antropomorfa, pois o ateísmo, caso não venha a ser reconsiderado a partir de aspectos recusados pela razão, reforçaria as instituições baseadas em princípios antropomorfos. Em suma, o ateísmo integral denotaria a supressão do princípio de identidade e, conseqüentemente, o banimento físico e moral da "propriedade do eu responsável”, levando assim à prostituição universal dos seres, a qual, por sua vez, seria um complemento da monstruosidade integral no sentido de uma ausência de normatividade.

Klossowski ressalta também que a exigência da transgressão se oporia aos efeitos do ateísmo, pois seria ainda possível que se desse a expropriação do eu corporal e moral "no sentido utópico do falanstério de Fourrier, baseado no "jogo das paixões” (KLOSSOWSKI, 1985, p. 21). Porém, caso esta "comunização" preconizada por Fourrier ocorresse, a tensão "necessária ao ultraje" se extinguiria levando ao fim o sadismo, a não ser que fossem propositalmente criadas regras do "jogo" a serem burladas, pois, para que ocorra a transgressão é necessária a existência de uma ordem, ou, isto é, de regras claras a serem seguidas.

Ainda a respeito da questão da transgressão, Klossowski sugere que a existência de normas faria com que se desse um "acúmulo" de energia, o que fatalmente transformaria a Anuário de Literatura vol. 13, n. 2, 2008, 1.20 
transgressão em um acontecimento necessário, pois a prostituição universal apenas "tem sentido em função da propriedade moral do corpo individual" (KLOSSOWSKI, 1985, p. 22). E, complementa o ensaísta, afirmando a necessidade de existência da noção de propriedade para que a prostituição não se prive daquilo que constitui seu incentivo, o ultraje.

No que tange à monstruosidade integral, que tacitamente habitaria a generalidade em vigor, o processo apenas descrito ocorreria de forma semelhante, pois a perversão, que seria a “insubordinação das funções de viver", através de seus procedimentos e, sobretudo, de sua ação principal, a prática da sodomia, obteria importância como ato transgressivo à medida que existissem normas estabelecidas. E, ainda, se se tomasse como correta a afirmação de que a perversão é, de certa forma, uma característica oculta do ser humano, como sugere Klossowski, é plausível que ela possa exercer a função de uma espécie de guia de transgressão para aqueles ditos "normais".

Outro ponto do ensaio de Klossowski que merece destaque diz respeito à sua advertência acerca de possíveis leituras ingênuas da obra de Sade. Para o pensador, se a monstruosidade integral se tornasse completa, no sentido de que houvesse apenas perversos confessos, seria possível considerar a "meta" de Sade alcançada. Isto é; o sadismo desapareceria pelo fato de não existir mais o monstro transgressor. (KLOSSOWSKI, 1985, p. 22).

A partir daí, pode-se extrair, seguindo o raciocínio de Klossowski, que a monstruosidade, ao contrariar regras, se afirmaria negativamente e, também, que são as próprias normas e instituições que criam um ambiente propício para que ocorram situações de perversão.

Uma outra observação de Klossowski, importante para a leitura de Medo de Sade, diz respeito ao comportamento do perverso, o qual sujeitaria "seu prazer à execução de um gesto único" (KLOSSOWSKI, 1985, p. 25); ou seja, mesmo em um meio efetivamente desregrado, o perverso se destacaria por uma "idéia fixa determinada". Paradoxalmente, aponta o autor, não haveria coisa menos livre do que o "gesto perverso", pois este gesto visa à busca por um detalhe. Dito de outra forma, o perverso se encontraria em uma constante procura pela realização de um feito exclusivo, o qual, pelo fato de ser único, pode ser realizado apenas uma vez. Ou, ainda: "a existência do perverso torna-se a perpétua expectativa do instante em que possa executar esse gesto", o qual é um fator essencial para que o perverso se signifique, ou seja, “executá-lo vale para a totalidade de existir" (KLOSSOWSKI, 1985, p. 25). 


\begin{abstract}
A esse respeito ele [o perverso] está aquém dos indivíduos mais grosseiros; mas enquanto essa insubordinação de uma só função só pode se concretizar e, em conseqüência, conseguir se individuar em seu próprio caso, ele sugere à reflexão de Sade uma possibilidade múltipla de redistribuição das funções e, normalmente, neste sentido, para além dos indivíduos "normalmente" constituídos, abre uma perspectiva mais vasta: a da polimorfia sensível. Salvo se, nas condições de vida da espécie humana, ele não possa afirmar a não ser destruindo estas condições em si mesmo: $O$ fato de existir consagra a morte da espécie humana em seu indivíduo. Ser se confirma como suspensão da própria vida. A perversão corresponderia assim a uma propriedade de ser alicerçada na expropriação das funções de viver. A expropriação do próprio corpo e de outrem será, em conseqüência, o sentido dessa propriedade de ser (KLOSSOWSKI, 1985, p. 25).
\end{abstract}

Para Sade, o principal tipo de perversão é a sodomia, pois é ela que faz com que se perceba similitudes entre os demais casos de perversão, o que possiblitaria a formação da monstruosidade integral. A sodomia seria ainda, no juízo de Sade, "um gesto específico de contrageneralidade", pois, ao golpear "a lei de propagação da espécie", "testemunha [...] a morte da espécie num indivíduo". Daí que o marquês entenda a sodomia como sendo o signo chave da perversão, pois, é o gesto perverso que "contém [o que há] de [mais] mortal para as normas da espécie" humana (KLOSSOWSKI, 1985, p. 27).

Neste ponto retomo Bataille e destaco sua discussão acerca da relação entre Sade e seu objeto. O autor entende que Sade foi possuído por seu objeto, pois para o marquês seria inconcebível a separação entre obra e objeto. Isto é: para Klossowski, o método de Sade consistiria em apontar e reproduzir seu sonho na origem de seu devaneio. (KLOSSOWSKI apud BATAILLE, s/d, p. 102-103).

Possivelmente foi o desenvolvimento dessa questão que levou Bataille a concluir que, ao contrário do cristão e do romântico, que respectivamente tomariam consciência de si próprios a partir da fé em Deus e da tomada de sua "paixão como um absoluto" (BATAILLE, s/d, p. 103), o sádico apenas perceba a si mesmo considerando o objeto que agrava seu vigor.

E qual seria o objeto do sádico? Segundo Bataille, um outro ser humano, sobre o qual deve necessariamente ser impresso um novo modo de ser para que se torne possível dele lograr a angústia e o desastre esperado. Portanto, o fato de se imprimir em alguém um novo modo de ser é, necessariamente, um ato planejado, diferença fundamental, ao que parece, entre o sádico e, talvez assim se possa dizer, "o simples sádico", que agiria de forma impensada.

A discussão de Nietzsche acerca do elemento inocente que compõe a maldade é útil para uma melhor compreensão desta questão:

A maldade não tem por objetivo o sofrimento do outro em si, mas nosso próprio prazer, em forma de sentimento de vingança ou de uma mais forte excitação nervosa, por exemplo. Já um simples gracejo demonstra como é prazeroso exercitar nosso poder sobre o outro e Anuário de Literatura vol. 13, n. 2, 2008, 1.22 
chegar ao agradável sentimento da superioridade. Então o imoral consiste em ter prazer a partir do desprezar alheio? É diabólica a satisfação com o mal alheio, como quer Schopenhauer? Na natureza obtemos prazer quebrando galhos, removendo pedras, lutando com animais selvagens, para nos tornarmos conscientes de nossa força. Saber que o outro sofre por nosso intermédio tornaria imoral a mesma coisa pela qual normalmente não nos sentimos responsáveis? Se não o soubéssemos, contudo, também não teríamos prazer em nossa própria superioridade, que justamente só se pode dar a conhecer no sofrimento alheio [...]. Em si mesmo o prazer não é bom nem mau; de onde viria a determinação de que, para ter prazer consigo, não se deveria suscitar o desprezar alheio? Unicamente do ponto de vista da utilidade, ou seja, considerando as conseqüencias, o desprezar eventual, quando o prejudicado ou o Estado que o representa leva a esperar punição e vingança: apenas isso, originalmente, pode ter fornecido o fundamento para negar a si mesmo tais ações (NIETZSCHE, 2000, p. 78-79).

No primeiro ato de Medo de Sade (CARVALHO, 2000) - o romance de Bernardo Carvalho é dividido em dois atos -, o barão de LaChafoi encontra-se em um local que presume ser Charenton, o hospício em que o marquês de Sade esteve internado entre 1803 e 1814, ano de sua morte, e onde costumava encenar peças teatrais com os demais internos. No interior de uma cela, que supunha completamente escura, já que não era capaz de enxergar ninguém, o barão dialoga com uma voz, a qual imagina pertencer ao marquês. À esta voz LaChafoi narra, em uma espécie de prestação de contas à seu ídolo, os acontecimentos que o levaram até lá - afinal de contas, para o barão libertino aquela voz pertencia a Sade, seu mestre.

Sucintamente é possível dizer que o barão procura respostas junto a seu suposto mestre para o que aconteceu de impróprio durante uma "noite de devassidão e excessos" (CARVALHO, 2000, p.13) no castelo de Lagrange, quando os participantes - sua esposa, seu primo, o conde de Suz e sua bela criada Martine - ingeriram uma fórmula afrodisíaca à base de cantáridas trituradas, a qual supostamente foi prescrita pelo próprio marquês; o barão busca respostas tendo em vista que após despertar desta noite libertina percebeu que um dos participantes da orgia foi assassinado e, pior, além do fato de ele não conhecer qual dos três outros participantes foi vitimado, ele próprio, então já encarcerado, estava sendo acusado de tal crime. Ou seja, ao que parece, talvez esta voz funcione como uma espécie de regra que regularia a ordem e o desenvolvimento de uma dada comunidade, no caso a dos libertinos e, por conseguinte, a vida do barão.

Entretanto, é apenas no segundo e último ato do romance de Carvalho, no qual o leitor é trazido para a contemporaneidade, que se percebe que aquela voz que em um primeiro 
momento regularia uma comunidade de libertinos impõe normas, na verdade, a um outro corpo social, aquele ao qual pertencem os que são considerados loucos.

É então a partir da narrativa do "negro de branco ao branco de branco" (CARVALHO, 2000 , p. 67) que tem início o entrelaçamento dos dois atos do romance. É atravées desta narrativa, a do "negro de branco", o qual poderia muito bem ter como profissão a enfermagem, que se fica sabendo que o interno do segundo ato, um cidadão francês, seguidor da filosofia libertina do barão de LaChafoi, que encomendou, na cidade do Rio de Janeiro, a morte de sua esposa, também cidadã francesa, acredita ser o próprio barão.

Em suma, de acordo com o narrador, o essencial seria conhecer o caráter paradoxal do crime e não quem foi seu autor, já que o o assassinato da mulher fora praticado para que se tornasse possível a execução de um outro crime, que, em virtude das circunstâncias, não foi e não poderá ser empreendido.

No entanto, creio ser relevante destacar um fragmento da caracterização do casal envolvido no crime, fragmento este que traz à tona as regras do jogo em que os dois personagens se envolveram.

\begin{abstract}
Era um casal curioso. [...] Casaram-se numa capelinha no alto de uma colina, a coisa mais singela, no sul da França, no vilarejo onde ele tinha nascido e onde no início do século XIX, ao que parece, um barão organizava bacanais inspirado no marquês de Sade. Um escritor libertino cuja filosofia máxima era a traição. Seis meses depois de casados descobriram que ela não podia ter filhos. Perceberam que o amor não resiste ao tempo, o amor acaba, e fizeram um pacto explícito que, de hábito, nos casamentos em geral, por ficar implícito, termina por destruí-los. Resolveram que o melhor era estabelecer uma relação baseada na traição e no horror. O horror no lugar do amor. Um casamento baseado num jogo de horrores, porque, como ele mesmo vive repetindo em suas crises, o horror não morre, ao contrário do amor. Só o horror pode manter um casamento, sob o princípio da traição, segundo a filosofia do tal barão libertino. Cada um dos cônjuges prega uma peça no outro, alternada e sucessivamente. O que aprenderam a chamar, numa brincadeira reservada entre os dois, de "medo de Sade". Uma referência ao célebre marquês, é lógico, que ao que tudo indica tinha inspirado o barão no início do século XIX em sua filosofia tão peculiar. [...] Quem tiver mais medo, perde. Esse era o jogo. [...] Só que o negócio durou pouco. Porque até a traição tem suas regras, e ele trapaceou. Quis adiantar a morte, matar a mulher antes que ela o matasse. Teve medo. E nesse jogo quem tem medo perde. Para você pode parecer um paradoxo, e para mim também, mas ao morrer ela ganhou. Ao morrer, ela ganhou porque deixou ele apavorado (CARVALHO, 2000, p. 68-69).
\end{abstract}

Conforme foi apontado anteriormente, Sade sugere a instituição de uma contrageneralidade que possibilite uma troca entre casos específicos de perversão, cuja particularidade seria a inexistência de estrutura lógica. 
A partir desta constatação é possível tecer algumas considerações a respeito da legitimidade de uma relação conjugal baseada na traição e no horror, como é o caso daquela mantida entre os personagens de Carvalho.

Em um primeiro momento, uma relação nestes moldes pode ser encarada como legítima, caso se concorde com o raciocínio de Nietzsche quando sugere que seria a coerção operada por um aparelho de estado, por exemplo, que impediria que se dessem comportamentos fora de uma generalidade já estabelecida.

Por outro lado, se se admite que um comportamento similar seja legítimo, e se, hipoteticamente, deixasse de existir todo e qualquer tipo de coerção em relação ao fato de que se obtenha prazer a partir do sofrimento alheio, seria instaurada a princípio uma espécie de desregramento total, que, por sua vez, impediria que alguém se impusesse, ou, ainda, obtivesse prazer através do sofrimento alheio e, por conseguinte, que demonstrasse sua superioridade sobre um outro ser.

No entanto, mesmo em uma situação como aquela reclamada por Sade, em que haveria a ausência total de normas, seriam reinstituídas regras a serem burladas, pois, ao que parece, para que haja a transgressão é imprescindível que se estabeleçam regras, mesmo que estas sejam tácitas e operem sobre comunidades restritas ou ainda um número ínfimo de pessoas.

A este respeito, é novamente possível tomar como exemplo o casal do romance de Carvalho, que, ao manterem uma relação baseada na traição e no horror, a qual, para um olhar externo pareceria completamente ilógica, no sentido de que não estaria baseada em regra alguma, possuem, na verdade, entre eles, apenas, seus próprios códigos e normas, através dos quais obtêm prazer a partir do sofrimento e do pavor do outro com o intuito de se manterem unidos.

É possível que o próprio marquês de Sade tivesse consciência da necessidade de existência de empecilhos como a linguagem logicamente estruturada das normas e das instituições para que se desse a monstruosidade integral, entendida aqui como a ausência total de normas, pois é a partir apenas do conceito de norma instituída que se percebe o que é monstruoso, ou, em outras palavras, o que é ilógico.

Daí que a lógica do casal do romance de Carvalho pareça ilógica para quem olha de fora, ainda que para eles, na busca incessante do prazer e da manutenção da relação, exista uma lógica apenas por eles conhecida. 
Esta busca peculiar e incessante pelo gozo por parte dos personagens, baseada em códigos próprios, os quais aparentemente desconsiderariam as coerções apontadas por Nietzsche, parece manter alguma relação com a discussão a respeito do fato de Sade ter sido, de acordo com Bataille, possuído por seu objeto, pois, ao que parece, a única forma através da qual os personagens tomam consciência de si próprios é a obtenção do prazer a partir do horror ao qual seu objeto, no caso um dos cônjuges, é submetido.

Para finalizar, é preciso destacar que a busca incessante da reiteração do horror, que no entanto seria único, ou ainda, a perseguição de uma "idéia fixa", como por exemplo a suposição do marido em relação à frase proferida por sua esposa, obsessão que o levou a perder o jogo, poderia ser encarada como aquilo que tornaria a existência dos personagens "a perpétua expectativa do instante em que possa executar esse gesto" (KLOSSOWSKI, 1985, p. 25).

\section{Referências}

BATAILLE, Georges. A literatura e o mal. Trad. Sueli Bastos. Porto Alegre: L\&PM, s/d.

CARVALHO, Bernardo. Medo de Sade. São Paulo: Companhia das Letras, 2000.

FOUCAULT, Michel. As palavras e as coisas. Trad. Salma Tannus Muchail. São Paulo: Martins Fontes, 2000.

KLOSSOWSKI, Pierre. Sade meu próximo. Trad. Armando Ribeiro. São Paulo: Brasiliense, 1985.

NIETZSCHE, Friedrich. Humano, demasiado humano - Um livro para espíritos livres. Trad., notas e posfácio: Paulo César de Souza. São Paulo: Companhia das Letras, 2000.

SÁ, Nelson. Bernardo Carvalho vai ao teatro com Sade. Disponível em

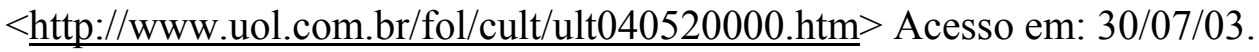

